\title{
Activity/rest rhythm of depressed adolescents undergoing therapy: case studies
}

\author{
Ritmo de atividade e repouso em adolescentes deprimidos durante terapia: \\ estudos de caso
}

\author{
Maria Eugênia Mesquita, ${ }^{1}$ Maria Eliza Finazzi, ${ }^{1}$ Bruno Gonçalves, ${ }^{1}$ Lee Fu-I,${ }^{2}$ Leandro L. Duarte, ${ }^{3}$ \\ José Ricardo Lopes, ${ }^{3}$ José Alberto Del-Porto, ${ }^{1}$ Luiz Menna-Barreto ${ }^{4}$
}

\begin{abstract}
Introduction: Disorders of circadian rhythms have been reported in studies of both depressed children and of depressed adolescents. The aim of this study was to evaluate whether there is a relationship between the 24-hour spectral power (24h SP) of the activity/rest rhythm and the clinical course of depression in adolescents.

Methods: Six 14 to 17 -year-old adolescents were recruited for the study. They were all suffering from major depressive disorder, according to the Diagnostic and Statistical Manual of Mental Disorders, 4th edition (DSM-IV) criteria, as identified by the Schedule for Affective Disorders and Schizophrenia for School Aged Children: Present and Lifetime Version (K-SADS-PL). Depressive symptoms were assessed using the Children's Depression Rating Scale - Revised (CDRS-R) and clinical evaluations. Locomotor activity was monitored over a period of 13 consecutive weeks. Activity was measured for 10-minute periods using wrist-worn activity monitors. All patients were prescribed sertraline from after the first week up until the end of the study.

Results: We found a relationship between high CDRS values and low 24-hour spectral power.

Conclusions: The $24 \mathrm{~h} \mathrm{SP}$ of the activity/rest rhythm correlated significantly (negatively) with the clinical ratings of depression.

Keywords: Circadian rhythms, chronobiology, spectral analysis, depression, adolescents.
\end{abstract}

\section{Resumo}

Introdução: Distúrbios do ritmo circadiano têm sido relatados em estudos com crianças e adolescentes deprimidos. O objetivo deste estudo foi avaliar se existe relação entre a potência espectral de 24 horas do ritmo de atividade e repouso e sintomas clínicos de depressão em adolescentes.

Métodos: Seis adolescentes com idade entre 14 e 17 anos foram recrutados para o estudo. Eles foram diagnosticados com depressão maior de acordo com os critérios do Manual Diagnóstico e Estatístico de Transtornos Mentais, $4^{a}$ edição (DSM-IV), identificados utilizando-se o instrumento Schedule for Affective Disorders and Schizophrenia for School Aged Children: Present and Lifetime Version (K-SADS-PL). Os sintomas depressivos foram avaliados pelo questionário Children's Depression Rating Scale - Revised (CDRS-R) e por avaliações clínicas. A atividade motora foi monitorada por um período de 13 semanas consecutivas e registrada a cada 10 minutos utilizando-se monitores de atividades usados no pulso. Todos os pacientes utilizaram o antidepressivo sertralina começando após a primeira semana até o final do estudo.

Resultados: Foi observada uma relação entre escores altos no CDRS-R e valores baixos de potência espectral de 24 horas no ritmo de atividade e repouso.

Conclusão: A potência espectral de 24 horas do ritmo de atividade e repouso apresentou uma correlação significativa (negativa) com os sintomas clínicos de depressão.

Descritores: Ritmos circadianos, cronobiologia, análise de potência espectral, depressão, adolescentes.

\footnotetext{
${ }^{1}$ Departamento de Psiquiatria, Escola Paulista de Medicina, Universidade Federal de São Paulo (UNIFESP), São Paulo, SP, Brazil. ${ }^{2}$ Departamento de Psiquiatria, Faculdade de Medicina, Universidade de São Paulo (USP), São Paulo, SP, Brazil. ${ }^{3}$ Departamento de Fisiologia e Biofísica, USP, São Paulo, SP, Brazil. ${ }^{4}$ Escola de Artes, Ciências e Humanidades, USP, São Paulo, SP, Brazil.

Financial support: none.

Submitted Sep 10 2015, accepted for publication Mar 15 2016. No conflicts of interest declared concerning the publication of this article.

Suggested citation: Mesquita ME, Finazzi ME, Gonçalves B, Fu-I L, Duarte LL, Lopes JR, et al. Activity/rest rhythm of depressed adolescents undergoing therapy: case studies. Trends Psychiatry Psychother. 2016;38(4):216-220. http://dx.doi.org/10.1590/2237-6089-2015-0053
} 


\section{Introduction}

A depressive state can be the final psychobiological response to circadian disturbances. ${ }^{1-3}$ A regular rhythm that is synchronized to the 24-hour light-dark cycle is associated with lower intensity of depressive symptoms. ${ }^{4-8}$ Depressive subtypes and severity of symptoms have also been linked to circadian disturbances, with a negative impact on outcome and treatment. ${ }^{9-11}$

Nowadays, therapies based on chronobiological principles are recognized as important strategies for treatment of mood disorders. ${ }^{12}$ The principle is to strengthen temporal cues such as light exposure and manipulate the stability of sleeping and social rhythms in order to synchronize biological rhythms to the 24-hour environmental cycle.

Adolescence is a time of life during which intense biological and psychosocial changes take place due to the process of maturation. ${ }^{13,14}$ The later waking-up and sleeping times observed after puberty have been attributed both to the process of maturation and to psychosocial factors such as late-night social activities, particularly in urban contexts. ${ }^{15,16}$ However, early school schedules, which are common during this stage of life, can conflict with biological time (the evening tendency) and may disturb circadian entrainment, leading to sleep deficits and to emotional and cognitive problems.

The main chronobiological theory for depression proposes that circadian rhythms in depression are characterized by a loss of power or stability. ${ }^{17,18}$ The $24 \mathrm{~h}$ spectral power ( $24 \mathrm{~h} \mathrm{SP}$ ) of a rhythm is evaluated by the percentage of how well the rhythmic data fit to a 24-hour oscillation ascertained by a variance spectral analysis. ${ }^{19}$ The $24 \mathrm{~h}$ SP can be interpreted as a parameter that reflects the degree of circadian entrainment. A higher 24h SP means better synchronization of biological rhythms to the environmental cycle.

Study of activity/rest rhythms by actigraphy has been highly recommended. This is a technique for monitoring locomotor activity using a wrist-worn device, the actimeter. This technique is accessible, does not cause patients discomfort and does not disturb the process being examined. ${ }^{20}$ Additionally, locomotor activity has both clinical importance and physiological meaning in depression.

Many researchers have described circadian rhythm disturbances of depressed adults. Several studies have reported blunting of the circadian amplitude of circadian patterns of plasma 3-methoxy-4-hydroxiphenylglycol (MHPG), ${ }^{9,21}$ of thyroid stimulating hormone, and of activity/rest rhythms. ${ }^{22-24}$ However, there are few studies of depressed children and adolescents in the literature. Studies of the 24-hour pattern of plasma cortisol have found no significant differences between depressed children and normal children used as controls. ${ }^{25,26}$ However, higher levels of cortisol were detected at the onset of sleep in depressive patients. These results were most marked in hospitalized or suicidal patients. ${ }^{27}$ Cavallo et al. reported a significant attenuation in mean 24-hour, nocturnal, and peak melatonin secretion in nine depressed children and adolescents compared with ten controls. ${ }^{28}$ Five of the depressed children had mean night time concentrations of melatonin outside the control range. Although no formal chronobiological analysis was conducted, this is one study identified by searching the literature that demonstrated blunting of circadian amplitude in depressed children.

Teicher et al. reported a reduction in circadian power (or fit) in depressed children and adolescents. ${ }^{20}$ They reported a decreased amplitude of the circadian activity/rest rhythm and an increased magnitude of semicircadian rhythm. Circadian rhythm accounted for $49.1 \pm 14.0 \%$ of variability in the activity profiles of normal controls and $35.5 \pm 10.5 \%$ of variability in patients with depressive disorders. These results were most marked in adolescents. Semicircadian amplitude differentiated between depressed patients and controls with $94 \%$ specificity and $84 \%$ sensitivity.

Monitoring locomotor activity of people in depressive states can be helpful to clarify the link between activity/ rest rhythm and depressive symptoms. Circadian activity/rest rhythm studies of depressed adolescents can thus contribute to the pathophysiology, prognostics and therapeutics of adolescent depression.

The objective of this study was to evaluate the correlation between the $24 \mathrm{~h}$ SP of the activity/rest rhythm and depressive symptoms along a 13-week course of treatment in adolescents with major depressive disorder (MDD).

\section{Methods}

Six adolescents, two boys and four girls, aged from 15 to 17, with diagnoses of first episodes of MDD according to Diagnostic and Statistical Manual of Mental Disorders, 4th edition (DSM-IV) criteria $^{29}$ were evaluated along the course of their treatment. The patients were selected from two outpatient services; the Ambulatório de Transtornos Afetivos, Serviço de Psiquiatria Infantil e da Adolescência, Hospital das Clínicas, Faculdade de Medicina, Universidade de São Paulo (FMUSP) and the Ambulatório do Programa de Doenças Afetivas, Departamento de Psiquiatria, Escola Paulista de Medicina, Universidade Federal de São Paulo (UNIFESP). Diagnoses were made on the basis of clinical interviews conducted 
by two expert psychiatrists. The Brazilian version of the Schedule for Affective Disorders and Schizophrenia for School Aged Children: Present and Lifetime Version (K-SADS-PL) ${ }^{23}$ was used to confirm MDD diagnosis and co-morbidities. The patients had no medical/neurological diseases and were not given medications that could alter circadian rhythms during the study. They were evaluated only after their parents or legal guardians had given written consent for participation and they had provided verbal consent themselves. The study protocol was approved by the ethics committees at both UNIFESP and FMUSP.

Motor activity was recorded by actimeters over a period of 13 consecutive weeks. The actimeter (MiniMitter Monitoring) is a small accelerometer worn on the non-dominant wrist, with memory for data storage. This device detects accelerations greater than $0.01 \mathrm{G}$ force (up to 10 counts per second). Actimeter data were processed individually. Time series with 10 minute intervals (between data points) and weekly intervals starting on Sundays were analyzed. These time intervals were submitted to the Sokolove-Bushell spectral analysis algorithm using El Temps software. ${ }^{30}$

During the 13-week period, the adolescents also kept activity diaries with their routine activities (school timetables, transport, start and end of sleep and other activities) that were based on a work shift diary. Initially we intended to monitor social activities but diary data were incomplete so we only used these data to evaluate possible masking factors, such as fever or physical exercises, and removal of the actimeter. ${ }^{31}$

Clinical assessments were carried out weekly and the Children's Depression Rating Scale - Revised (CDRS-R) was used to assess depressive symptoms. According to this scale, total scores of 40 or more are strong indicators of the presence of an MDD 32 and remission was defined as when the total score was lower than 40 .

All patients received sertraline as an antidepressant treatment, but their doses were individually adjusted to achieve decrease or remission of symptoms. Four patients were on $50 \mathrm{mg} /$ day and two patients were on $100 \mathrm{mg} /$ day from after the first week until the end of the study. The 13-week period was chosen because it is the mean time taken to achieve a response to treatment manifest as decrease or remission of symptoms.

The correlation between the CDRS-R scores and $24 \mathrm{~h}$ SP values was assessed by calculating Spearman's coefficient $(p<0.05)$. The CDRS-R scores were used to classify each week as either a week with depression (DP) or a week with no depression (NDP) and the spectral power values were compared between these two groups. The Wilcoxon rank sum test was used for this statistical analysis.

\section{Results}

Six subjects ( 2 males and 4 females) were enrolled on the study. Their ages ranged from 15 to 17 . Table 1 lists demographic characteristics, co-morbidities diagnosed (according DSM-IV criteria) and school and work schedules.

Table 2 lists the 24h SP values for the circadian activity/rest rhythm and CDRS-R scores over the period of 13 consecutive weeks.

Analysis of the correlation between CDRS and 24h $\mathrm{SP}$ returned values of $r=-0.47$ and $p<0.001$. Mean $24 \mathrm{~h}$ SP was higher in weeks in which CDRS was less than 40 in five of the subjects (Table 3). Subject 6 exhibited a higher mean $24 \mathrm{~h}$ SP in the weeks he was depressed (CDRS greater than or equal to 40 ). The overall analysis detected a significant difference between weeks with and without depression ( $p=$ 0.0032) (Table 3).

\section{Discussion}

To our knowledge, this is the first study of circadian activity/rest rhythms along the course of treatment of depressed adolescents. Our results demonstrate a relationship between the $24 \mathrm{~h}$ SP of the patients' activity/rest rhythms and their depressive state. Lower $24 \mathrm{~h}$ SP values were observed during depressive states and higher $24 \mathrm{~h} \mathrm{SP}$ were observed when symptoms were in remission or attenuated. These results support the theory of loss of circadian power in depressive state.

Table 1 - Demographics, DSM-IV co-morbidities diagnosed, school and work schedules and sleep phase delay at weekends

\begin{tabular}{lccccc}
\hline Subjects & Sex & Age & Co-morbidities diagnosed & Schedules school/work & Sleep phase delay \\
\hline 1 & M & 17 & Dysthymic disorder & Not studying & No \\
2 & F & 17 & Dysthymic disorder & Morning & Present \\
3 & F & 15 & PTSD & Morning & Present \\
4 & M & 17 & Dysthymic disorder & Night & No \\
5 & F & 16 & Dysthymic disorder & Morning & Present \\
6 & F & 17 & Bulimia & Night & No \\
\hline
\end{tabular}

DSM-IV = Diagnostic and Statistical Manual of Mental Disorders, 4th edition; F = female; $\mathrm{M}=$ male; PTSD = posttraumatic stress disorder. 
Table $\mathbf{2}$ - CDRS-R scores and 24h SP values weekly over 13 weeks

\begin{tabular}{|c|c|c|c|c|c|c|c|c|c|c|c|c|c|c|}
\hline Subjects & Weeks & 1 & 2 & 3 & 4 & 5 & 6 & 7 & 8 & 9 & 10 & 11 & 12 & 13 \\
\hline \multirow{2}{*}{1} & CDRS-R & 78 & 75 & 68 & 58 & 59 & 64 & 60 & 60 & 48 & & & 48 & 37 \\
\hline & $24 h \mathrm{SP}$ & 31 & 20 & 18 & 24 & 25 & 26 & 15 & 15 & 28 & & & 14 & 55 \\
\hline \multirow{2}{*}{2} & CDRS-R & 58 & 58 & 51 & 56 & 38 & 42 & 41 & 49 & 23 & 23 & 29 & 46 & \\
\hline & $24 h$ SP & 36 & 43 & 40 & 30 & 38 & 46 & 45 & 42 & 47 & 47 & & & \\
\hline \multirow{2}{*}{3} & CDRS-R & 84 & 42 & 63 & 81 & 57 & 90 & 28 & & 27 & & 33 & 39 & 34 \\
\hline & $24 h \mathrm{SP}$ & 31 & 31 & 32 & 34 & 36 & 32 & & 41 & 31 & 37 & & & 44 \\
\hline \multirow{2}{*}{4} & CDRS-R & 67 & 78 & 47 & 44 & 36 & 63 & 44 & 70 & 55 & & 46 & & \\
\hline & $24 \mathrm{~h} \mathrm{SP}$ & 29 & 34 & 40 & 33 & 34 & 25 & 29 & 31 & 35 & 35 & 41 & 40 & 24 \\
\hline \multirow{2}{*}{5} & CDRS-R & 72 & 66 & 65 & 54 & 69 & 54 & 28 & 26 & & 60 & & & \\
\hline & 24h SP & 38 & 39 & 36 & 35 & 32 & 33 & 37 & 40 & 33 & 33 & 39 & & \\
\hline \multirow{2}{*}{6} & CDRS-R & 72 & 49 & 52 & 32 & 31 & 18 & 19 & 17 & & 46 & & & 28 \\
\hline & $24 \mathrm{~h} \mathrm{SP}$ & 43 & 48 & 50 & 40 & 45 & 31 & 41 & 49 & 37 & 43 & 46 & & \\
\hline
\end{tabular}

$24 \mathrm{~h} \mathrm{SP}=24 \mathrm{~h}$ spectral power; CDRS-R $=$ Children's Depression Rating Scale - Revised. Blanks correspond to missing data.

Table 3 - Mean 24h SP weeks with and without depression

\begin{tabular}{lcccc}
\hline & \multicolumn{2}{c}{ CDRS } & \multicolumn{2}{c}{ 24h SP } \\
\cline { 2 - 5 } Subjects & DP & NDP & DP & NDP \\
\hline 1 & 61.8 & 37 & 21.6 & 55 \\
2 & 50.7 & 28 & 40.3 & 44 \\
3 & 69.5 & 30.5 & 32.7 & 37.5 \\
4 & 57.1 & 36 & 33 & 34 \\
5 & 62.9 & 27 & 35.1 & 38.5 \\
6 & 54.7 & 23.4 & 46 & 41.2 \\
Total & 59.6 & 27.8 & 33 & 41.3 \\
p-value & $<0.0001$ & \multicolumn{2}{c}{0.0032} \\
\hline
\end{tabular}

$24 \mathrm{~h} \mathrm{SP}=24 \mathrm{~h}$ spectral power; CDRS $=$ Children's Depression Rating Scale - Revised; DP = weeks with depression; NDP = weeks without depression.

Clinical improvement was associated with the highest $24 \mathrm{~h}$ SP values in five patients (numbers 1 to 5). Patient 1 who presented later improvement (only in the 13th week) had lower mean $24 \mathrm{~h}$ SP during the depressed phase. Patient 6 had higher mean 24h SP and took less time to recover (four weeks). Teicher et al. observed that depressed children with adequately entrained $24 \mathrm{~h}$ circadian rhythms took less time to recover from depression without medications then children with circadian disturbances. ${ }^{33}$ Previous studies have also shown an increase in gross motor activity in depressed patients following successful treatment. ${ }^{24,29,34}$

The only discrepant result (patient 6 ) suggests that circadian disorders may be present in some but not all depressive states, which is probably related to subtypes of depression ${ }^{23}$ or to depressive severity. ${ }^{29}$ One possibility is that this patient had a well synchronized rhythm (the first three weeks with depression had high spectral power values). It would therefore be difficult to increase the spectral power in the following weeks.

It is important to note that monitoring locomotor activity over the 13 weeks of treatment allowed us to compare the patient with themselves in terms of their individual data for depressive state, social schedules and rhythms.

Limitations of this study include the small size of the sample that is insufficient to allow generalizations, so further replications are needed; and the fact that no controls not on antidepressant treatment were included. However, prior studies have reported the $24 \mathrm{~h}$ patterns of normal controls and shown that the effects of medication on circadian rhythms were due to their impact on core depressive symptoms. ${ }^{29,34}$ Additionally, we were unable to distinguish unipolar from bipolar depression with certainty, and depression in adolescents can be the first episode of bipolar disorder.

The amount of data for each patient assessed in this study was not uniform (see blanks in Table 2) and these differences were due to missed clinical assessments and to problems with recording of actimeter data.

These results support the model of circadian attenuation (loss of circadian power) during depression. ${ }^{17,18}$ Furthermore, the temporal coincidence between clinical improvement and increase in $24 \mathrm{~h}$ SP suggests a possible temporal link between improvement of symptoms and entrainment of circadian rhythms.

Analysis of circadian dysregulation may contribute to understanding the pathogenesis of depression and to evaluation of therapeutic efficacy and provides a potentially useful tool for prognostic assessment and therapeutic management of adolescent depression.

The National Institute of Mental Health has recently released its Research Domain Criteria (RDoC). The RDoC is an initiative to improve classification of mental health and open new lines of research based on examining patients' responses with biological measures. ${ }^{35}$ The actimeter is one methodology that is provided for within the RDoC framework as a means of measuring synchronization to the light/dark cycle outside. This study shows the feasibility of using this tool to help in clinical follow-up. 


\section{Acknowledgements}

This study was partially supported by Fundação de Amparo à Pesquisa do Estado de São Paulo (FAPESP; grant 01/0435-5). We gratefully acknowledge the help of Mr. José Ricardo Lopes and Dr. Rosa Maria Mesquita.

\section{References}

1. Wehr TA, Goodwin FK. Biological rhythms in manic-depressive illness. In: Wehr TA, Goodwin FK, editors. Circadian rhythms in psychiatry. Pacific Grove: Boxwood; 1983. p. 129-84.

2. Akiskal HS. Transtornos do humor: introdução e panorama. In: Kaplan I, Sadock BJ, editores. São Paulo: Artmed; 1999. p. 1175-87.

3. Yanielli PC. Cronobiología de la ansiedad e de la depresión mayor. In: Golombeck D. Cronobiología humana: ritmos y relojes biológicos en la salud y en la enfermedad. Quilmes: Universidad Nacional Quilmes; 2002. p. 171-86.

4. Brown LF, Reynolds CF 3rd, Monk TH, Prigerson HG, Dew MA, Houck PR, et al. Social rhythm stability following late-life spousal bereavement: associations with depression and sleep impairment. Psychiatry Res. 1996;62:161-9.

5. Prigerson HG, Reynolds CF 3rd, Frank E, Kupfer DJ, George C], Houck PR. Stressful life events, social rhythms, and depressive symptoms among the elderly: an examination of hypothesized causal linkages. Psychiatry Res. 1994;51:33-49.

6. Szuba MP, Yager A, Guze BH, Allen EM, Baxter LR Jr. Disruption of social circadian rhythms in major depression: a preliminary report. Psychiatry Res. 1992;42:221-30.

7. Luik AI, Zuurbier LA, Direk N, Hofman A, Van Someren EJ, Tiemeier H. 24-hour activity rhythm and sleep disturbances in depression and anxiety: a population-based study of middleaged and older persons. Depress Anxiety. 2015;32:684-92.

8. Wirz-Justice A, Bromundt V, Cajochen C. Circadian disruption and psychiatric disorders: the importance of entrainment. Sleep Med Clin. 2009;4:273-84.

9. Souêtre $E$, Salvati E, Belegou JL, Pringuey D, Candito M, Krebs $B$, et al. Circadian rhythms in depression and recovery: evidence for blunted amplitude as the main chronobiological abnormality. Psychiatry Res. 1989;28:263-78.

10. Ávila Moraes C, Cambras T, Diez-Noguera A, Schimitt R, Dantas $\mathrm{G}$, Levandovski $\mathrm{R}$, et al. A new chronobiological approach to discriminate between acute and chronic depression using peripheral temperature, rest-activity, and light exposure parameters. BMC Psychiatry. 2013;13:77.

11. Luik AI, Zuurbier LA, Hofman A, Van Someren EJ, Tiemeier H. Stability and fragmentation of the activity rhythm across the sleep-wake cycle: the importance of age, lifestyle, and mental health. Chronobiol Int. 2013;30:1223-30.

12. Hickie IB, Naismith SL, Robillard R, Scott EM, Hermens DF. Manipulating the sleep-wake cycle and circadian rhythms to improve clinical management of major depression. BMC Med. 2013;11:79.

13. Goodwin FK and Jamison KR. Childhood and adolescence. In: Goodwin FK, Jamison KR, editors. Maniac-depressive illness. New York: Oxford University; 1990. p. 186-209.

14. McCauley E, Pavlidis K, Kendall K. Developmental precursors of depression: the child and the social environment. In: Goodyer IM, editor. The depressed child and adolescent. Cambridge: Cambridge University; 2001. p. 204-32.

15. de Souza CM, Hidalgo MP. Midpoint of sleep on school days is associated with depression among adolescents. Chronobiol Int. 2014;31:199-205.

16. Carissimi A, Dresch F, Martins AC, Levandovski RM, Adan A, Natale $V$, et al. The influence of school time on sleep patterns of children and adolescents. Sleep Med. 2016;19:33-9.
17. Siever LJ, Davis KL. Overview: toward a dysregulation hypothesis of depression. Am J Psychiatry. 1985;142:1017-31.

18. Schulz $H$, Lund $R$. On the origin of early REM episodes in the sleep of depressed patients: a comparison of three hypotheses. Psychiatry Res. 1985;16:65-77.

19. Sokolove PG, Bushell WN. The chi square periodogram: its utility for analysis of circadian rhythms. J Theor Biol. 1978;72:131-60.

20. Teicher MH, Glod CA, Harper D, Magnus E, Brasher C, Wren F, et al. Locomotor activity in depressed children and adolescents: I. Circadian dysregulation. J Am Acad Child Adolesc Psychiatry. 1993;32:760-9.

21. Gwirtsman HE, Halaris AE, Wolf AW, DeMet E, Piletz JE, Marler M. Apparent phase advance in diurnal MHPG rhythm in depression. Am J Psychiatry. 1989;146:1427-33.

22. Kupfer DJ, Weiss BL, Foster G, Detre TP, McPartland R. Psychomotor activity in affective states. Arch Gen Psychiatry. 1974;30:765-8.

23. Benoit O, Royant-Parola S, Borbely AA, Tobler I, Windlocher D. Circadian aspects of motor activity in depressed patients. Acta Psychiat Belg. 1985;85:582-92.

24. Raoux N, Benoit O, Dantchev N, Denise P, Franc B, Allilaire JF, et al. Circadian pattern of motor activity in major depressive patients undergoing antidepressant therapy: relationship between actigraphic measures and clinical course. Psychiatry Res. 1994;52:85-98.

25. Dahl R, Puig-Antich J, Ryan N, Nelson B, Novacenko H, Twomey J, et al. Cortisol secretion in adolescents with major depressive disorder. Acta Psychiatr Scand. 1989;80:18-26.

26. Puig-Antich J. Affective disorders in children and adolescents: diagnostic validity and psychobiology. In: Meltzer HY, editor Psychopharmacology the third generations of progress. New York: Raven Press; 1987. p. 843.

27. Dahl R, Ryan ND, Puig-Antich J, Nguyen NA, al-Shabbout $M$, Meyer VA, et al. 24-hour cortisol measures in adolescents with major depression: a controlled study. Biol Psychiatry. 1991;30:25-36.

28. Cavallo A, Holt KG, Jejazi MS, Richards GE, Meyer WJ 3rd. Melatonin circadian rhythm in childhood depression. J Am Acad Child Adolesc Psychiatry. 1987;26:395-9.

29. Aronen ET, Teicher MH, Geenens D, Curtin S, Glod CA, Pahlavan K. Motor activity and severity of depression in hospitalized prepubertal children. J Am Acad Child Adolesc Psychiatry. 1996;35:752-63.

30. El Temps: the chronobiologist's program [Internet]. 1999 [cited 2015 Jul 9]. el-temps.com/principal.html

31. Fisher FM. Método de avaliação do ritmo de trabalho e repouso entre condutores de veículos. In: 10 Congresso Brasileiro de Segurança do Tráfego; 1985; São Paulo, Brasil.

32. Poznanski EO, Mokros HB. Children's Depression Ranting Scale, Revised (CDRS-R). Los Angeles: Western Psychological Services; 1996.

33. Teicher MH, Glod CA, Pahlavan K, Magnus E, Harper D. Circadian activity dysregulation and antidepressant response in children and adolescents. In: Scientific Proceedings of the 37th Meeting of the American Academy of Child and Adolescent Psychiatry; 1990; Chicago, USA. vol. VI, p. 58.

34. Godfrey HP, Knight RG. The validity of actometer and activity speech measures in the assessment of depressed patients. $\mathrm{Br}$ ] Psychiatry. 1984;145:159-63.

35. Insel T, Cuthbert B, Garvey M, Heinssen R, Pine DS, Quinn K, et al. Research domain criteria (RDoC): toward a new classification framework for research on mental disorders. Am J Psychiatry. 2010;167:748-51.

\section{Correspondence:}

Bruno Gonçalves

Rua Pedro de Toledo, 669

04039-032 - São Paulo, SP - Brazil

E-mail: brunocrono@hotmail.com 